\title{
Serosurvey and molecular detection of the main zoonotic parasites carried by commensal Rattus norvegicus populations in Tehran, Iran
}

Taher Azimi ( $\sim$ Taherazimi5@gmail.com )

Tehran University of Medical Sciences https://orcid.org/0000-0003-0213-5227

Mohammad Reza Pourmand

Tehran University of Medical Sciences

Fatemeh Fallah

Shaheed Beheshti University of Medical Sciences

Abdollah Karimi

Shaheed Beheshti University of Medical Sciences

Roxana Mansour-Ghanaie

Shaheed Beheshti University of Medical Sciences

Seyedeh Mahsan Hoseini-Alfatemi

Shaheed Beheshti University of Medical Sciences

Mehdi Shirdoust

Shaheed Beheshti University of Medical Sciences

Leila Azimi ( $\square$ leilaazimi1982@gmail.com )

Shaheed Beheshti University of Medical Sciences

\section{Research}

Keywords: Zoonotic parasites, Rattus norvegicus, Leishmania spp, Toxoplasma gondii, Giardia spp,

Tehran

Posted Date: March 28th, 2020

DOl: https://doi.org/10.21203/rs.3.rs-19380/v1

License: (c) (1) This work is licensed under a Creative Commons Attribution 4.0 International License. Read Full License

Version of Record: A version of this preprint was published at Tropical Medicine and Health on July 22nd, 2020. See the published version at https://doi.org/10.1186/s41182-020-00246-3. 


\section{Abstract}

Background: Rattus norvegicus are reservoirs of various zoonotic parasites that have become a global public health concern. Considering the distribution of Rattus norvegicus throughout Tehran, this study aims to assess the frequency of zoonotic parasites carried by commensal rodents in Tehran, Iran.

Methods: The study considered five regions (North, South, West, East, and center) of Tehran as case studies. The serological method was used for detecting antibodies against Trichomonas vaginalis , Babesia spp, and Cryptosporidium spp using a commercial qualitative rat ELISA kit. The frequency of Toxoplasma gondii was surveyed by the conventional PCR method. Furthermore, nested PCR was used to detect Giardia spp and Leishmania spp in commensal Rattus norvegicus in Tehran.

Results: Approximately, $76 \%$ of 100 Rattus norvegicus tested were infected with at least one zoonotic parasite, which demonstrates the significant frequency of parasites within the study areas. Seroreactivity against Trichomonas vaginalis , Babesia spp, and Cryptosporidium spp was detected in $5 \%, 0 \%$, and $1 \%$ of Rattus norvegicus tested, respectively. Toxoplasma gondii DNA was detected in 32 out of $100(32 \%)$ Rattus norvegicus , and Leishmania spp and Giardia spp DNA were found in 18 out of 100 (18\%) and 76 out of 100 (76\%) Rattus norvegicus investigated, respectively.

Conclusion: The findings indicate a wide geographical dissemination of Giardia spp, Toxoplasma gondii , and Leishmania spp DNA in Rattus norvegicus within five districts of Tehran. In contrast, other parasites such as Cryptosporidium spp infection rarely occurred in Rattus populations. No evidence for the circulation of Babesia spp was found in this study.

\section{Introduction}

Zoonotic parasites cause a significantly high rate of human infectious diseases [1]. It is predicted that sixty-one percent of pathogens, which are recognized to infect individuals, can cause zoonotic diseases [2]. Zoonotic parasites are transmitted between animals and persons with or without vectors; however, eating foods contaminated by rodent feces or urine and inhaling the germ in feces of rodents are considered the most important pathways for parasite transmission [3, 4, 5]. Rattus norvegicus globally live and feed in close proximity to human populations and are known to carry various pathogens including bacteria, viruses, and parasites [6]. In urban areas, Rattus norvegicus act as a reservoir of zoonotic pathogens, especially zoonotic parasites, and hold a connection to various important hygienic problems; they are also responsible for human morbidity and mortality, worldwide [7]. Many of these zoonotic parasites including Leishmania spp, Giardia spp, Toxoplasma gondii, Trichomonas vaginalis, and Cryptosporidium spp are assumed to be endemic in Rattus norvegicus populations around the world $[8,9,10,11]$. Currently, approximately seventy-nine species of rodents have been recognized in Iran; among these previously identified rodents, Rattus norvegicus have shown greater frequency in the urban area and occupied widespread habitats in cities [12]. Although it has been proven that these rats have a potential role in the transmission of a large number of zoonotic parasites, the prevalence and diversity of 
parasites in urban Rattus norvegicus populations remain unknown and, also, the data concerning zoonotic parasites of Rattus norvegicus are quite insufficient. So far, a comprehensive parasitological assessment of Rattus norvegicus populations in the case of Tehran, Iran has not been conducted. Therefore, the present study performs a comprehensive survey of Rattus norvegicus collected in five districts of Tehran for zoonotic parasites. These are the first informative data on zoonotic parasites related to Rattus norvegicus in urban areas of Tehran, Iran.

\section{Materials And Methods}

\section{Site selection and sample collection}

The study was conducted in five regions (North, South, West, East, and center) of Tehran. All the trapping locations were selected in urban areas in alleys behind the residential dwellings. The sampling strategy was designed to trap a similar number of rats between October 2018 and June 2019. The rodent samplings were carried out using Sherman live traps and suitable baits through the convenient sampling method. The aggregated places of rats were found around dumping garbage sites along the water open canal and gardens. Due to the physical and chemical intervention of Tehran Municipality aimed at controlling rats, the catching of rodents is problematic; therefore, a prebaiting procedure is preferable for improving the efficiency of traps. The trapping was carried out after sundown in each selected region and processed during midnight or the next morning. The traps were distributed in order to cover the present situation. The collected rodents were transferred to a guaranteened special laboratory in animal houses and were euthanized by the intramuscular injection of Ketamine and Xylazine $(0.1 \mathrm{mg} / \mathrm{kg})$ followed by bilateral thoracotomy. Finally, faecal samples were collected and blood was obtained by cardiac puncture using a $5 \mathrm{~mL}$ syringe; then, serum was recovered after centrifugation and stored at $-80^{\circ} \mathrm{C}$ until serological analysis. The subsequent parasitological examination was performed at the Department of Microbiology of Shahid Beheshti University of Medical Sciences.

\section{Enzyme-linked immunosorbent assay (ELISA)}

Serum samples were screened for antibodies against Trichomonas vaginalis, Babesia spp, and Cryptosporidium spp using commercial qualitative rat ELISA kit (Shanghai Crystal day Biotech Co., Ltd) according to the manufacturer's instructions. The optical density (OD value) of each well was measured immediately using a microplate reader set at $450 \mathrm{~nm}$ (OD450) within 15 minutes after adding the stop solution (sulfuric acid).

\section{DNA extraction and Polymerase Chain Reaction (PCR)}

Genomic DNA was extracted from fecal samples using the DNA extraction kit (AllPrep DNA minikit (Qiagen, Inc.) according to the manufacturer's guidelines, and each DNA sample was eluted in 200 ख of elution buffer preserved at $-80 \mathrm{oC}$ until the future use. PCR was conducted for the detection of Toxoplasma gondii using specific primer pairs. The sequence of primers used for PCR reaction is shown in Table 1. PCR was conducted at a final volume of $25 \mu \mathrm{L}$ including $0.5 \mu \mathrm{l}$ of $10 \mathrm{mM}$ of each 
deoxynucleoside triphosphate (dNTPs), $3 \mu$ of 10x PCR buffer without $\mathrm{MgCl} 2,2.5 \mathrm{mmol} / \mathrm{L} \mathrm{MgCl} 2,1$ unit of Taq polymerase (Cinnagene, Iran), $0.5 \mu \mathrm{M}$ of each primer $(10 \mathrm{mM}), 3 \mu$ l of template DNA, and $7.5 \mu \mathrm{L}$ of sterile distilled water. Amplification reactions were performed under the following condition: one cycle of $95^{\circ} \mathrm{C}$ for 4 min, followed by 36 cycles of $94^{\circ} \mathrm{C}$ for $45 \mathrm{~s}$, annealing at $56^{\circ} \mathrm{C}$ for $45 \mathrm{~s}$, and preserving $72{ }^{\circ} \mathrm{C}$ for 1 minute with the final extension at $72^{\circ} \mathrm{C}$ for 10 minutes following the last cycle. PCR products were screened on a $1 \%-1.5 \%$ agarose gel, visualized by DNA safe stain (SinaClon Co., Iran), and photographed under UV light. Moreover, PCR amplified products were confirmed by sequencing analysis (Macrogen Korea), and the obtained sequence results were examined by the NCBI BLAST program (Primer blast).

\section{Nested PCR}

Nested PCR was used for the detection of Giardia spp and Leishmania spp using specific primer pairs. Briefly, Leishmania DNA was amplified and detected using the first-round primer pairs including 5'CTGGATCATTTTCCGATG-3' and 5'-TGATACCACTTATCGCACTT-3' and the second-round primers including 5'-CATTTTCCGATGATTACACC-3' and 5'-CGTTCTTCAACGAAATAGG-3'. The PCR conditions for the first step were based on a previously published study by Poonam et al. [13]. On the other hand, Giardia spp DNA was amplified using the first round and second round primers, as shown in Table 2. The PCR conditions for the first step were based on a previously published study by Adnan et al[14]. In summary, PCR was conducted at a final volume of $50 \mu$ including $10 \mathrm{mM}$ Tris- $\mathrm{HCl}(\mathrm{pH} \mathrm{8.3)}$ and $50 \mathrm{mM}$ $\mathrm{KCl}$, a $200 \mu \mathrm{M}$ concentration of each dNTP, $1.5 \mathrm{mM} \mathrm{MgCl}_{2}, 1.25 \mathrm{U}$ of Taq DNA polymerase (Invitrogen), 50 ng of each primer, $5 \mu \mathrm{LNA}$, and $1 \times$ PCR buffer (Invitrogen). For the second round, the method provided by Gannavaram et al. was used [15]. Briefly, the second round was performed at the total volume of $50 \mu \mathrm{l}$ containing $10 \mathrm{mM}$ Tris- $\mathrm{HCl}(\mathrm{pH} \mathrm{8.3),} 50 \mathrm{mM} \mathrm{KCl}, 200 \mathrm{mM}$ of each dNTP, $1.5 \mathrm{mM} \mathrm{MgCl} 2,2 \mathrm{mM}$ of each primer, and 1.5 U Platinum Taq DNA Polymerase (Invitrogen). Moreover, we used $1 \mu \mathrm{l}$ of the diluted (1:10) products from the first-round reaction as a template. Amplification reactions were performed under the following condition: initial denaturation at $94^{\circ} \mathrm{C}$ for 5 min followed by 35 cycles of $94^{\circ} \mathrm{C}$ for 1 minute, annealing at $50-54^{\circ} \mathrm{C}$ for 1 minute, and preserving $72{ }^{\circ} \mathrm{C}$ for $90 \mathrm{~s}$ with the final extension at $72^{\circ} \mathrm{C}$ for 3 minutes. PCR products were screened on a $1 \%$ agarose gel, visualized by DNA safe stain (SinaClon Co., Iran), and photographed under UV light; they were confirmed by sequencing analysis (Macrogen Korea). The sequencing results were examined by the NCBI BLAST program (Primer blast).

\section{Statistical analysis}

The data was formatted in an SPSS file, and the frequency of each surveyed parasite was analyzed by the statistical package SPSS v.23.0 (SPSS Inc., Chicago, IL, USA) using descriptive statistic tests.

\section{Results}

\section{Detection of Trichomonas vaginalis, Babesia spp, and Cryptosporidium spp}

A total of 100 live Rattus norvegicus (20 rats from each district of Tehran) were captured and surveyed in order to determine their zoonotic parasites. To evaluate the seroprevalence of Trichomonas vaginalis, 
Babesia spp, and Cryptosporidium spp in the trapped rats, the presence of rat IgG antibodies was examined by ELISA kit. In total, results of serological assay revealed that of the 100 rats captured in Tehran, $5 \%(n=5 / 100)$ and $1 \%(n=1 / 100)$ were positive for Trichomonas vaginalis and Cryptosporidium $s p p$, respectively. Among five different districts, Trichomonas vaginalis had the highest frequency $(15 \%, \mathrm{n}$ $=3 / 20$ ) among Rattus norvegicus collected from the western part of Tehran. However, this parasite was not detected in the northern and central parts of Tehran. On the other hand, Cryptosporidium spp was detected only in one rat, collected from the central part of Tehran. Babesia spp was not detected in the any serum samples of all 100 animals examined.

\section{Detection of Toxoplasma gondii, Giardia spp, and Leishmania spp}

In this study, PCR method was used to screen the presence of Toxoplasma gondii in fecal samples, collected from Rattus norvegicus. Moreover, Nested PCR was used for detecting Giardia spp and Leishmania spp using specific primer pairs. The number of Rattus norvegicus and sample types positive for zoonotic parasites in five districts of Tehran are shown in Table 3. Results showed that the percentage of positive animals in the five regions of Tehran for Toxoplasma gondii was $32 \%$. Among Rattus norvegicus trapped in Tehran, Toxoplasma gondii had the highest and lowest frequency in the north (70\%, $n=14 / 20)$ and west $(5 \%, n=1 / 20)$ districts, respectively. Leishmania spp ELISA analysis of serum samples resulted in the detection of 18 out of $100(18 \%)$ seropositive samples, originating from northern $(15 \%, n=3 / 20)$, southern $(15 \%, n=3 / 20)$, eastern $(15 \%, n=3 / 20)$, western $(15 \%, n=3 / 20)$, and central $(30 \%, n=6 / 20)$ parts of Tehran. Giardia spp has the highest frequency among surveyed parasites. In general, according to the results of Nested PCR assay, of the 100 rats captured in Tehran, $76 \%(n=$ $76 / 100)$ were positive for Giardia spp, originating from eastern $(95 \%, n=19 / 20)$, central $(80 \%, n=16 / 20)$, southern $(75 \%, n=15 / 20)$, western $(65 \%, n=13 / 20)$, and northern $(65 \%, n=13 / 20)$ parts of Tehran.

\section{Discussion}

In general, in the urban area, rodents such as Rattus norvegicus exist in large populations and represent a significant reservoir of a range of human pathogens including bacteria, viruses, and parasites $[6,16]$. In comparison to other mammalian species, Rattus norvegicus live and feed in closer proximity to humans. These rodents harbor and disseminate zoonotic parasites through their ectoparasites or via biological materials; therefore, they play an active and main role in the transmission of various zoonotic diseases $[17,18]$. Tehran as the capital of Iran is a large city in the north of the country that features a continentalinfluenced Hot-summer Mediterranean climate. Home to a population of about 10-12 million in the city and 15 million over the larger metropolitan area of Greater Tehran, Tehran is the most populous city in Iran and Western Asia and has the second largest metropolitan area in the Middle East [19, 20, 21]. However, the prevalence and diversity of parasites in Rattus norvegicus populations in Tehran remain unknown, and a comprehensive parasitological assessment of Rattus norvegicus populations has not been conducted so far. The result of our study revealed that Giardia spp was the main parasite that was frequently $(76 \% ; n=76 / 100)$ isolated from the Rattus population of Tehran. In addition, the frequency of Giardia spp was very high in the eastern $(95 \%, n=19 / 20)$ part of Tehran. This result was in contrast to 
those of published studies of Carolina and Tiwari in Brazil and India, respectively. These studies found that the frequency of Giardia spp in the Rattus norvegicus population was $17.1 \%$ and $42.9 \%$, respectively $[22,23]$. On the other hand, the result of our study revealed that Toxoplasma gondii had the highest frequency $(70 \% ; n=14 / 20)$ among Ratti captured from the northern part of Tehran. The total frequency of Toxoplasma gondii was $32 \%$. These results were similar to those of published studies conducted by Dellarupe and Chao Yan. They revealed that the frequency of Toxoplasma gondii in the Rattus norvegicus population in Argentina and China was $32.8 \%$ and $23.9 \%$, respectively [24, 25]. However, Pellizzaro et al. in Brazil [8], Saki et al. from Ahvaz province of Iran [10], Gennari from Brazil [9], and Cheng Yin from China [26] showed that the frequency of Toxoplasma gondii in Rattus population was $4.6 \%, 6 \%, 8.6 \%$, and $3.2 \%$, respectively. Generally, the high frequency of Giardia spp and Toxoplasma gondii in the Rattus population in Tehran is an important concern. Accordingly, humans and animals have been infected mainly by the ingestion of oocysts in the environment or consumption of foods containing cysts of Toxoplasma gondii [11]; therefore, sanitary control is extremely important to observe in Tehran. Moreover, these data will help veterinarians and physicians to better plan diagnostic and preventative measures. The frequency of Leishmania positive Rattus population was $18 \%$ lower than what has been found in other studies. For example, Motazedian et al. (2010) detected Leishmania major (52\%) in the Rattus population in Iran [27]; Marcelino et al. (2011) detected Leishmania (36.25\%) in the Rattus population in Brazil [28]; Dohlen et al. (2018) detected Leishmania (23.3\%) in the Rattus population in the USA[29]; Tsakmakidis et al. (2017) detected Leishmania (70\%) in the Rattus norvegicus population in Greece [30]. On the other hand, Echchakery et al. (2017) detected Leishmania (11.11\%) in the Rattus population in Morocco [31]. Leishmaniasis is a vector-borne infectious disease and is considered to be a major public health problem in the urban environment. The diagnosis of natural hosts of Leishmania spp in urban areas is critical and will facilitate a better understanding of the epidemiology of the Leishmaniasis [32].

In conclusion, this finding indicates that the Rattus norvegicus population is a significant reservoir of Giardia spp, Toxoplasma gondii, and Leishmania spp infection for humans in Tehran. It is important to raise public attention to and awareness of the transmission risk of illness to people through the Rattus population. Information about zoonotic parasites carried by the Rattus norvegicus population in Tehran province is critical to developing suitable surveillance plans and intervention strategies.

\section{Declarations}

\section{Funding}

The research reported in this publication was supported by Elite Researcher Grant Committee under award no. [962763] from the National Institutes for Medical Research Development (NIMAD), Tehran, Iran.

\section{Ethics approval and consent to participate}

The present study was approved by the Ethics Committee of National Institutes for Medical Research Development (NIMAD) with reference number IR.NIMAD.REC. 1396.323. All authors of this research paper 
have directly participated in the planning, execution, or analysis of this study.

\section{Consent for publication}

All authors made substantial contributions to the conception and design, acquisition of data, or analysis and interpretation of data. They played an active role in drafting the article or revising it critically to achieve important intellectual content, gave the final approval of the version to be published, and agreed to be accountable for all aspects of the work.

Competing interests: The authors declare that they have no competing interests.

Data Availability Statement: All data generated or analysed during this study are included in this published article.

\section{References}

1. Galán-Puchades MT, Sanxis-Furió J, Pascual J, Bueno-Marí R, Franco S, Peracho V, et al. First survey on zoonotic helminthosis in urban brown rats (Rattus norvegicus) in Spain and associated public health considerations. Veterinary parasitology. 2018;259:49-52.

2. Cantas L, Suer K. the important bacterial zoonoses in "one health" concept. Frontiers in public health. 2014;2:144.

3. Meerburg BG, Singleton GR, Kijlstra A. Rodent-borne diseases and their risks for public health. Critical reviews in microbiology. 2009;35 3:221-70.

4. Guenther S, Bethe A, Fruth A, Semmler T, Ulrich RG, Wieler LH, et al. Frequent combination of antimicrobial multiresistance and extraintestinal pathogenicity in Escherichia coli isolates from urban rats (Rattus norvegicus) in Berlin, Germany. PloS one. 2012;7 11:e50331.

5. Maas M, De Vries A, Reusken C, Buijs J, Goris M, Hartskeerl R, et al. Prevalence of Leptospira spp. and Seoul hantavirus in brown rats (Rattus norvegicus) in four regions in the Netherlands, 20112015. Infection ecology \& epidemiology. 2018;8 1:1490135.

6. Firth C, Bhat M, Firth MA, Williams SH, Frye MJ, Simmonds P, et al. Detection of zoonotic pathogens and characterization of novel viruses carried by commensal Rattus norvegicus in New York City. MBio. 2014;5 5:e01933-14.

7. Himsworth CG, Bai Y, Kosoy MY, Wood H, DiBernardo A, Lindsay R, et al. An investigation of Bartonella spp., Rickettsia typhi, and Seoul hantavirus in rats (Rattus spp.) from an inner-city neighborhood of Vancouver, Canada: is pathogen presence a reflection of global and local rat population structure? Vector-Borne and Zoonotic Diseases. 2015;15 1:21-6.

8. Pellizzaro M, Conrado FdO, Martins CM, Joaquim SF, Ferreira F, Langoni H, et al. Serosurvey of Leptospira spp. and Toxoplasma gondii in rats captured from two zoos in Southern Brazil. Revista da Sociedade Brasileira de Medicina Tropical. 2017;50 6:857-60. 
9. Gennari SM, Ogrzewalska MH, Soares HS, Saraiva DG, Pinter A, Nieri-Bastos FA, et al. Toxoplasma gondii antibodies in wild rodents and marsupials from the Atlantic Forest, state of São Paulo, Brazil. Revista Brasileira de Parasitologia Veterinária. 2015;24 3:379-82.

10. Saki J, Khademvatan S. Detection of Toxoplasma gondii by PCR and mouse bioassay in rodents of Ahvaz District, Southwestern Iran. BioMed research international. 2014;2014.

11. Murata FH, Cerqueira-Cézar CK, Kwok OC, Tiwari K, Sharma RN, Su C, et al. Role of rats (Rattus norvegicus) in the epidemiology of Toxoplasma gondii infection in Grenada, West Indies. Journal of Parasitology. 2018;104 5:571-3.

12. Rabiee MH, Mahmoudi A, Siahsarvie R, Kryštufek B, Mostafavi E. Rodent-borne diseases and their public health importance in Iran. PLoS neglected tropical diseases. 2018;12 4:e0006256.

13. Salotra P, Sreenivas G, Pogue GP, Lee N, Nakhasi HL, Ramesh V, et al. Development of a speciesspecific PCR assay for detection of Leishmania donovani in clinical samples from patients with kalaazar and post-kala-azar dermal leishmaniasis. Journal of Clinical Microbiology. 2001;39 3:849-54.

14. Ayan A, Ural DA, Erdogan H, Kilinc OO, Gültekin M, Ural K. PREVALANCE AND MOLECULAR CHARACTERIZATION OF GIARDIA DUODENALIS IN LIVESTOCK IN VAN, TURKEY.

15. Sreenivas G, Ansari N, Kataria J, Salotra P. Nested PCR assay for detection of Leishmania donovani in slit aspirates from post-kala-azar dermal leishmaniasis lesions. Journal of clinical microbiology. 2004;42 4:1777-8.

16. Himsworth CG, Feng AY, Parsons K, Kerr T, Patrick DMJUE. Using experiential knowledge to understand urban rat ecology: a survey of Canadian pest control professionals. 2013;16 2:341-50.

17. Gardner-Santana L, Norris D, Fornadel C, Hinson E, Klein SL, Glass GJMe. Commensal ecology, urban landscapes, and their influence on the genetic characteristics of city-dwelling Norway rats (Rattus norvegicus). 2009;18 13:2766-78.

18. Cavia R, Cueto GR, Suárez OVJL, Planning U. Changes in rodent communities according to the landscape structure in an urban ecosystem. 2009;90 1-2:11-9.

19. Azimi T, Nasiri MJ, Zamani S, Hashemi A, Goudarzi H, Fooladi AAl, et al. High genetic diversity among Mycobacterium tuberculosis strains in Tehran, Iran. 2018;11:1-6.

20. Azimi T, Shariati A, Fallah F, Imani Fooladi AA, Hashemi A, Goudarzi H, et al. Mycobacterium tuberculosis genotyping using MIRU-VNTR typing. 2017;27 149:40-8.

21. Sharifipour S, Rad KDJNM, Infections N. Seroprevalence of Hepatitis E virus among different age groups in Tehran, Iran. 2019:100638.

22. Chagas CRF, Gonzalez IHL, Favoretto SM, Ramos PLJAop. Parasitological surveillance in a rat (Rattus norvegicus) colony in São Paulo Zoo animal house. 2017;63 4:291-7.

23. Tiwari K, Springer CC, Chikweto A, Tang J, Sepulveda Y, Smith AL, et al. Giardiasis: Serum antibodies and coproantigens in brown rats (Rattus norvegicus) from Grenada, West Indies. 2018;11 3:293.

24. Dellarupe A, Fitte B, Pardini L, Campero LM, Bernstein M, Robles MdR, et al. Toxoplasma gondii and Neospora caninum infections in synanthropic rodents from Argentina. 2019;28 1:113-8. 
25. Yan C, Liang L-J, Zhang B-B, Lou Z-L, Zhang H-F, Shen X, et al. Prevalence and genotyping of Toxoplasma gondii in naturally-infected synanthropic rats (Rattus norvegicus) and mice (Mus musculus) in eastern China. 2014;7 1:591.

26. Yin C-C, He Y, Zhou D-H, Yan C, He X-H, Wu S-M, et al. Seroprevalence of Toxoplasma gondii in rats in southern China. 2010;96 6:1233-5.

27. Motazedian MH, Parhizkari M, Mehrabani D, Hatam G, Asgari QJV-B, Diseases Z. First detection of Leishmania major in Rattus norvegicus from Fars province, southern Iran. 2010;10 10:969-75.

28. Marcelino AP, Ferreira EC, Avendanha JS, Costa CF, Chiarelli D, Almeida G, et al. Molecular detection of Leishmania braziliensis in Rattus norvegicus in an area endemic for cutaneous leishmaniasis in Brazil. 2011;183 1-2:54-8.

29. von Dohlen AR, Cheathem N, Tiwari K, Sharma RNJVw. Prevalence of antibodies against visceralizing Leishmania spp. in brown rats from Grenada, West Indies. 2018;11 9:1321.

30. Tsakmakidis I, Angelopoulou K, Dovas Cl, Dokianakis E, Tamvakis A, Symeonidou I, et al. Leishmania infection in rodents in Greece. 2017;22 12:1523-32.

31. Echchakery M, Chicharro C, Boussaa S, Nieto J, Carrillo E, Sheila O, et al. Molecular detection of Leishmania infantum and Leishmania tropica in rodent species from endemic cutaneous leishmaniasis areas in Morocco. 2017;10 1:454.

32. Eder M, Cortes F, de Siqueira Filha NT, de França GVA, Degroote S, Braga C, et al. Scoping review on vector-borne diseases in urban areas: transmission dynamics, vectorial capacity and co-infection. 2018;7 1:90.

\section{Tables}

Table 1. Primers used for the detection of the Toxoplasma gondii

\begin{tabular}{lll}
\hline Primers & ('Primer sequence $\left(5^{\prime}->3\right.$ & Amplicon size \\
& & \\
\hline Forward & GTAGCGTGCTTGTTGGCGAC & Variable \\
& & \\
\hline Reverse & ACAAGACATAGAGTGCCCC & \\
& & \\
\hline
\end{tabular}

Table 2. Primers used for the detection of the Giardia lamblia using nested PCR method. 


\begin{tabular}{ccc}
\hline First round & G7 F & 5-AAGCCCGACGACCTCACCCGCAGTGC-3 \\
\cline { 2 - 3 } & G759 R & 5-GAGGCCGCCCTGGATCTTCGAGACGAC-3 \\
\hline Second round & BG1 F & 5-GAACGAGATCGAGGTCCG-3 \\
\cline { 2 - 3 } & BG2 R & 5-CTCGACGAGTTCGTGTT-3
\end{tabular}

Table 3: Numbers of Rattus norvegicus and sample types positive for zoonotic parasites identified by ELISA, PCR, and Nested PCR methods in five districts of Tehran.

\begin{tabular}{|c|c|c|c|c|c|c|c|c|}
\hline \multirow[t]{2}{*}{ Zoonotic parasites } & \multirow[t]{2}{*}{ Sample type } & \multirow[t]{2}{*}{ Methods } & \multicolumn{5}{|c|}{$\begin{array}{c}\text { No. of positive } \\
\text { samples/no. tested in five districts of Tehran }\end{array}$} & \multirow{2}{*}{$\begin{array}{c}\text { No. of positive } \\
\text { samples/no. tested } \\
\text { Total }\end{array}$} \\
\hline & & & North & South & West & East & Center & \\
\hline Leishmania spp & Fecal & Nested PCR & $3 / 20$ & $3 / 20$ & $3 / 20$ & $3 / 20$ & $6 / 20$ & $18 / 100$ \\
\hline Giardia lamblia & Fecal & Nested PCR & $13 / 20$ & $15 / 20$ & $13 / 20$ & $19 / 20$ & $16 / / 20$ & $76 / 100$ \\
\hline Trichomonas vaginalis & Serum & ELISA & $0 / 20$ & $1 / 20$ & $3 / 20$ & $1 / 20$ & $0 / 20$ & $5 / 100$ \\
\hline Babesia spp & Serum & ELISA & $0 / 20$ & $0 / 20$ & $0 / 20$ & $0 / 20$ & $0 / 20$ & $0 / 100$ \\
\hline Cryptosporidium spp & Serum & ELISA & $0 / 20$ & $0 / 20$ & $0 / 20$ & $0 / 20$ & $1 / 20$ & $1 / 100$ \\
\hline Toxoplasma gondii & Fecal & PCR & $14 / 20$ & $6 / 20$ & $1 / 20$ & $5 / 20$ & $6 / 20$ & $32 / 100$ \\
\hline
\end{tabular}

\section{Supplementary Files}

This is a list of supplementary files associated with this preprint. Click to download.

- Graphicalabstract.docx 